\title{
Serum Protein Profiling Reveals a Landscape of Inflammation and Immune Signaling in Early-stage COVID-19 Infection
}

\section{Authors}

Xin Hou, Xiaomei Zhang, Xian Wu, Minya Lu, Dan Wang, Meng Xu, Hongye Wang, Te Liang, Jiayu Dai, Hu Duan, Yingchun Xu, Xiaobo Yu, and Yongzhe Li

\section{Correspondence}

yongzhelipumch@126.com; yuxiaobo@mail.ncpsb.org

\section{In Brief}

We performed an in-depth proteomics analysis of serum of early COVID-19 patients using a high-density antibody microarray. We identified a large set of differentially expressed proteins $(n=132)$ that constitute a landscape of inflammation and immune signaling related to the SARS-CoV-2 infection. Furthermore, the significant correlations of neutrophil and lymphocyte with the CCL2 and CXCL10 mediated cytokine signaling pathways were observed. These information are valuable for the understanding of COVID-19 pathogenesis, identification of biomarkers and development of the optimal anti-inflammation therapy.

\section{Graphical Abstract}

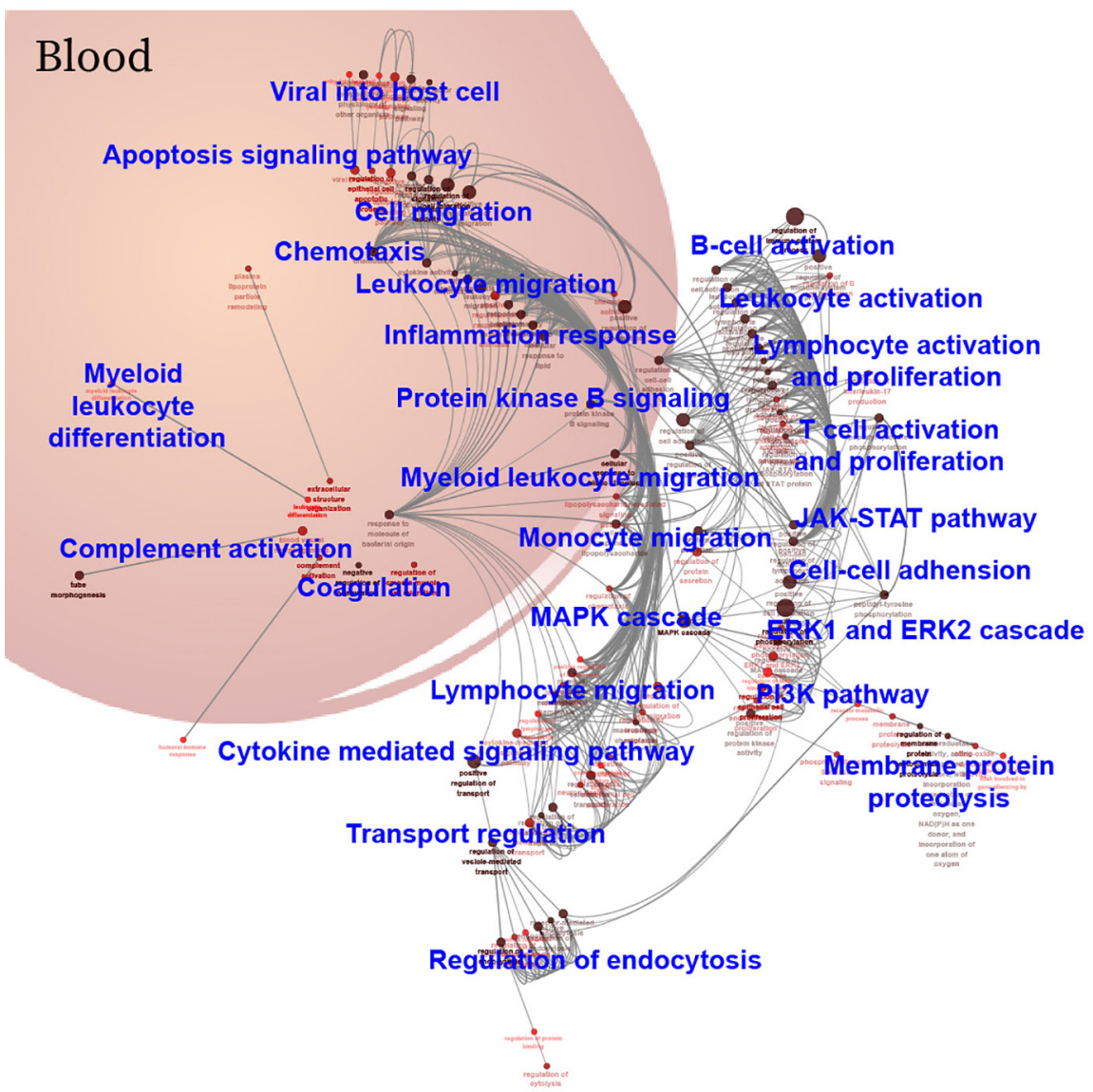

\section{Highlights}

- In-depth profiling of the serum proteome in early-stage COVID-19 patients.

- A landscape of inflammation and immune signaling related to the SARS-CoV-2 infection.

- CCL2 and CXCL10 medicated cytokine signaling pathways may correlate with neutrophil and lymphocyte respectively.

Hou et al., 2020, Mol Cell Proteomics 19(11), 1749-1759

November 2020 @ 2020 Hou et al. Published under exclusive license by The American Society for Biochemistry and Molecular Biology, Inc.

https://doi.org/10.1074/mcp.RP120.002128 


\title{
Serum Protein Profiling Reveals a Landscape of Inflammation and Immune Signaling in Early-stage COVID-19 Infection
}

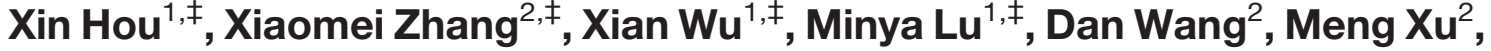 \\ Hongye Wang ${ }^{2}$, Te Liang ${ }^{2}$, Jiayu Dai ${ }^{2}$, Hu Duan ${ }^{2}$, Yingchun $\mathrm{Xu}^{1, *}, \mathrm{Xiaobo} \mathrm{Yu}^{2, *} \oplus$, \\ and Yongzhe $\mathrm{Li}^{1, *}$
}

Coronavirus disease 2019 (COVID-19) is a highly contagious infection and threating the human lives in the world. The elevation of cytokines in blood is crucial to induce cytokine storm and immunosuppression in the transition of severity in COVID-19 patients. However, the comprehensive changes of serum proteins in COVID-19 patients throughout the SARS-CoV-2 infection is unknown. In this work, we developed a high-density antibody microarray and performed an in-depth proteomics analysis of serum samples collected from early COVID-19 $(n=15)$ and influenza ( $n=13$ ) patients. We identified a large set of differentially expressed proteins $(n=132)$ that participate in a landscape of inflammation and immune signaling related to the SARS-CoV-2 infection. Furthermore, the significant correlations of neutrophil and lymphocyte with the CCL2 and CXCL10 mediated cytokine signaling pathways was identified. These information are valuable for the understanding of COVID-19 pathogenesis, identification of biomarkers and development of the optimal anti-inflammation therapy.

The corona virus disease 2019 (COVID-19) is caused by the severe acute respiratory syndrome coronavirus 2 (SARSCoV-2) and is highly contagious (1, 2). As of May 04, 2020, $3,524,429$ cases of infection and 247,838 COVID-19 related deaths have been reported worldwide. The most common symptoms of COVID-19 are fever, malaise, fatigue, dry cough, conjunctivitis, diarrhea, and pneumonia (3). Although $19 \%$ of infected patients develop severe pneumonia or multiple organ failure, $81 \%$ have only mild symptoms or are asymptomatic. Individuals who are asymptomatic are a major challenge in controlling the COVID-19 pandemic because they are still contagious (4).
Recent studies have reported that COVID-19 patients with severe symptoms have elevated plasma levels of IL2, IL6, IL7, IL10, GCSF, IP10, MCP1, MIP1A, and TNF $\alpha$ (3, 5-7), which suggests that the progression of COVID-19 is associated with cytokine storms and immunosuppression. Further profiling of the proteins in serum may help to understand the pathogenesis of COVID-19 and to develop effective treatment $(8,9)$. However, to date, there is neither a vaccine to prevent COVID-19 nor an effective medicine to treat COVID-19.

In this study, a comprehensive analysis of serological proteins from patients in the early stages of COVID-19 or influenza was performed using an antibody microarray developed in our laboratory (10). Many differentially-expressed proteins were identified that mediates diverse immune signaling pathways related to viral infection, the inflammatory response, and immune cell activation and migration. These data reflect the host response to COVID-19 infection, thus providing insight into COVID-19 pathogenesis and providing potential therapeutic targets.

\section{EXPERIMENTAL PROCEDURES}

Samples-All COVID-19 and influenza patients were enrolled in the outpatient department of the Peking Union Medical College Hospital (Peking, China). Serum samples were collected with written informed consent under the approval of the intuitional review board (IRB) from the Peking Union Medical College Hospital (Ethical number: ZS-2303) and the Beijing Proteome Research Center (Beijing, China). All experiments were performed according to the standards of the Declaration of Helsinki. All COVID-19 patients with mild or moderate symptoms were positively diagnosed in accordance with the Diagnosis and Management Plan of Pneumonia with Novel Coronavirus Infection (trial version 7).

Screening of COVID-19 Serum Proteome Using Antibody Microarrays-The antibody microarrays and sera screening were

From the ${ }^{1}$ Department of Clinical Laboratory \& Beijing Key Laboratory for Mechanisms Research and Precision Diagnosis of Invasive Fungal Diseases, Peking Union Medical College Hospital, Chinese Academy of Medical Science \& Peking Union Medical College, Beijing, China;

${ }^{2}$ State Key Laboratory of Proteomics, Beijing Proteome Research Center, National Center for Protein Sciences-Beijing (PHOENIX Center),

Beijing Institute of Lifeomics, Beijing, China

This article contains supplemental data.

*For correspondence: Yongzhe Li, yongzhelipumch@126.com; Xiaobo Yu, yuxiaobo@mail.ncpsb.org; Yingchun Xu, xycpumch@139.com.

${ }^{\ddagger}$ These authors contributed equally to this work. 
A

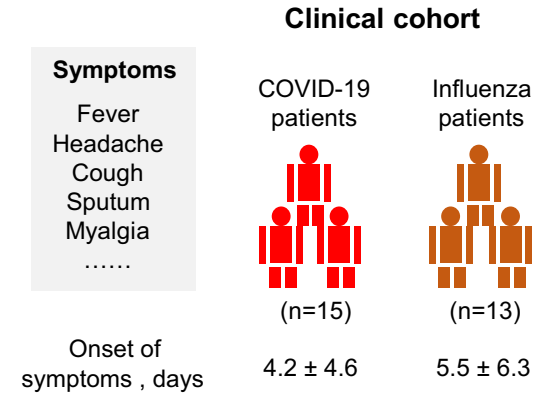

C

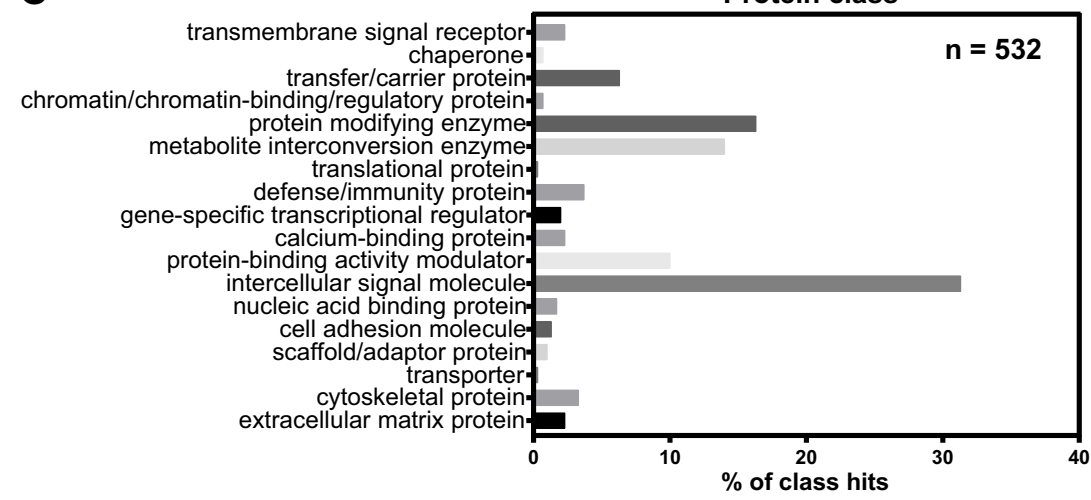

D

B

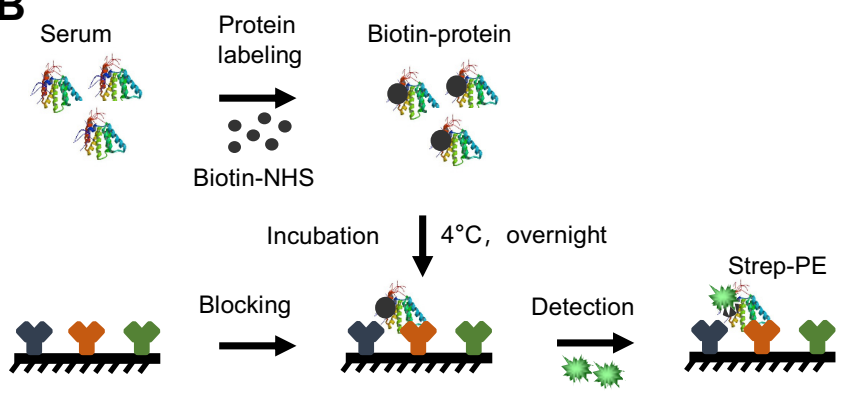

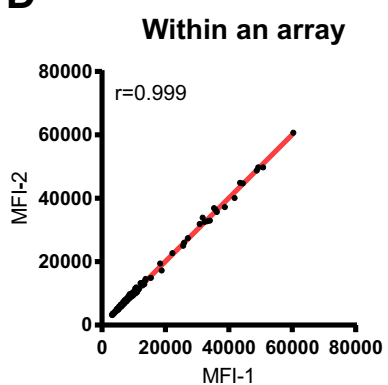

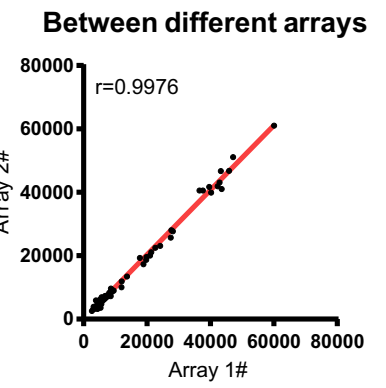

FIG. 1. Schematic illustration of serum screening of early-stage CoVID-19 patients. $A$, Characteristics of the clinical cohort used in this study. All enrolled COVID-19 patients displayed with the symptoms (i.e. fever, headache, cough sputum, myalgia) were diagnosed in accordance to the Diagnosis and Management Plan of Pneumonia with Novel Coronavirus Infection (trial version 7). The detail clinical information of each COVID-19 patient is shown in the supplemental Table S1. B, Workflow for serum screening using the antibody microarray. The proteins in serum was labeled with biotin and incubated with the blocked antibody microarray overnight at $4^{\circ} \mathrm{C}$. The biotin-proteins captured on microarray can be detected with streptavidin-Phycoerythrin (strep-PE) at the wavelength of $532 \mathrm{~nm}$. C, Classes of proteins on the antibody microarray. GO analysis (protein class) was performed using the PANTHER database (http://pantherdb.org/). D, Reproducibility of the antibody microarray for the detection of serum proteins. The correlation ( $r$ ) within an array and different arrays were calculated using the microarray data within an experiment and different experiments, respectively.

processed as previously described (10). Briefly, $10 \mu \mathrm{l}$ of serum were diluted with $90 \mu \mathrm{l}$ PBS (PBS; $\mathrm{pH} 7.4$ ) and labeled with $1 \mu$ l of NHSPEG4-Biotin (20 g/L in DMSO) (Thermo Fisher Scientific, MA) for $1 \mathrm{~h}$ at room temperature. After removing the excess biotin molecules, the biotinylated proteins were dissolved in $400 \mu$ l of PBS containing $5 \%$ milk (w/v). In parallel with biotin labeling, antibody microarrays were blocked with $500 \mu \mathrm{l}$ of PBS with $5 \%$ milk (w/v) for $1 \mathrm{~h}$ at room temperature. After removing the milk, the arrays were incubated with biotin-labeled proteins at $4{ }^{\circ} \mathrm{C}$ overnight. The slides were washed with PBS containing $0.05 \%(\mathrm{w} / \mathrm{v})$ Tween 20 (PBST). To detect the bound proteins, the arrays were incubated with $2 \mu \mathrm{g} / \mathrm{ml}$ streptavidinPhycoerythrin (PE) (Jackson Immunoresearch, PA) for $1 \mathrm{~h}$ at room temperature in the dark and then washed with PBST. After centrifuging for 2 min at $1000 \times g$, the slide was scanned using the GenePix 4300 A microarray scanner at the wavelength of $532 \mathrm{~nm}$.

Bioinformatics Analysis - Functional annotation of protein classes was performed using the PANTHER database (http://pantherdb.org/) (11). The GO biological process analysis was performed using CluGO and visualized in Cytoscape (version 3.7.2) using two-sided hypergeometric test with a p-value less than $0.01(12,13)$. The analyses of signaling pathways, protein domains and cellular components were performed using the STRING database (14).

Statistical Analysis - Differentially-expressed proteins were identified using the $\mathrm{t}$-distributed $t$ test ( $\mathrm{p}$-value $=0.05$ ). Hierarchical clustering was performed using the Mev software $(15,16)$.

\section{RESULTS}

In-Depth Profiling of the Serum Proteome in Early-Stage COVID-19 and Influenza Patients-The COVID-19 status of twenty-eight patients with similar symptoms (i.e. fever, headache, cough sputum, myalgia) were ascertained via RT-PCR, which detects SARS-CoV-2 RNA. In addition, the patients were tested 2-4 days from symptom onset. Fifteen (15) patients were positive for COVID-19 whereas 13 patients were negative for COVID-19; this latter group was classified as influenza (Fig. $1 A$, Table I, and supplemental Table S1). The proteins in the serum were measured using an antibody microarray containing 532 antibodies developed in-house and as previously described (supplemental Table S2, Fig. 1B) (10). The antibodies on the array target intercellular signaling molecules, protein-binding activity modulators, protein modifying enzymes and metabolite interconversion enzymes (Fig. 1C). The intra- and inter-reproducibility of the microarray are 0.9976 and 0.999 , respectively (Fig.1D).

Using a t-distributed $t$ test, 88 up-regulated and 37 down-regulated proteins between COVID-19 and influenza group patients were identified ( $p$-value $<0.05$ ) (Fig. $2 A$ and 
TABLE I

Characteristics of early-stage COVID-19 patients

\begin{tabular}{|c|c|c|}
\hline & $\begin{array}{c}\text { Influenza } \\
\text { Patients }(n=13)\end{array}$ & $\begin{array}{c}\text { COVID-19 } \\
\text { Patients }(n=15)\end{array}$ \\
\hline Male & $8(61.5 \%)$ & $7(46.7 \%)$ \\
\hline Female & $5(38.5 \%)$ & $8(53.3 \%)$ \\
\hline Age, year & $57.0(20.0-90.0)$ & $41.0(6.0-68.0)$ \\
\hline SARS-CoV-2 $(+)$ & 0 & $15(100 \%)$ \\
\hline FluA-RNA (+) & $6(46.2 \%)$ & 0 \\
\hline FluB RNA (+) & $3(23 \%)$ & 0 \\
\hline RSV RNA (+) & $4(30.8 \%)$ & 0 \\
\hline \multicolumn{3}{|l|}{ Disease stage } \\
\hline Mild & $5(38.5 \%)$ & $4(26.7 \%)$ \\
\hline Moderate & / & $11(73.3 \%)$ \\
\hline Severe & $7(53.8 \%)$ & 0 \\
\hline Critical & $1(7.7 \%)$ & 0 \\
\hline Exposure history & $4(30.8 \%)$ & $14(93.3 \%)$ \\
\hline \multicolumn{3}{|l|}{ Symptoms } \\
\hline Fever & $13(100 \%)$ & $11(73.3 \%)$ \\
\hline Headache & $4(30.8 \%)$ & $1(6.7 \%)$ \\
\hline Cough & $6(46.2 \%)$ & $7(46.7 \%)$ \\
\hline Sputum & $3(23.1 \%)$ & $2(13.3 \%)$ \\
\hline Myalgia & $7(53.8 \%)$ & $2(13.3 \%)$ \\
\hline Fatigue & $6(46.2 \%)$ & 0 \\
\hline Dyspnea & $1(7.7 \%)$ & $2(13.3 \%)$ \\
\hline Nasal congestion/Rhinorrhoea & $4(30.8 \%)$ & $4(26.7 \%)$ \\
\hline Sore throat & $4(30.8 \%)$ & $5(33.3 \%)$ \\
\hline Pleuritic chest pain & $1(7.7 \%)$ & $2(13.3 \%)$ \\
\hline Abdominal pain & $1(7.7 \%)$ & $1(6.7 \%)$ \\
\hline Diarrhea & $1(7.7 \%)$ & 0 \\
\hline Nausea or vomiting & 0 & 0 \\
\hline Asymptom & 0 & $2(13.3 \%)$ \\
\hline $\begin{array}{l}\text { Onset of symptom, } \\
\text { Median } \pm \text { S.D., days }\end{array}$ & $5.5 \pm 6.3$ & $4.2 \pm 4.6$ \\
\hline Pneumonia & $8(61.5 \%)$ & $11(73.3 \%)$ \\
\hline \multicolumn{3}{|l|}{ Chest CT } \\
\hline Pulmonary ground-glass opacity & $7(53.8 \%)$ & $11(73.3 \%)$ \\
\hline Bilateral pulmonary infiltration & $6(46.2 \%)$ & $10(66.7 \%)$ \\
\hline Administrated drugs & 0 & 0 \\
\hline \multicolumn{3}{|l|}{ Comorbidities } \\
\hline Pulmonary diseases & 0 & $1(6.7 \%)$ \\
\hline Cardiovascular diseases & $2(15.4 \%)$ & 0 \\
\hline Tumor & $1(7.7 \%)$ & 0 \\
\hline Endocrine diseases & $2(15.4 \%)$ & 0 \\
\hline None & $8(61.5 \%)$ & $14(93.3 \%)$ \\
\hline
\end{tabular}

Data are median (IQR) or $n(\%)$.

$2 B$, supplemental Table S3). Among them, the elevation of five cytokines (IFNG, IL6, CXCL8, CXCL10, and CCL2) were reported in mild and severe COVID-19 patients (Fig. $2 C)(8,17,18)$. These results demonstrate that the microarray is reliable in detecting serum proteins from COVID19 patients. Many differentially expressed proteins not reported to be associated with COVID-19 infection were also detected, including IL20, CCL27, IL21, PLG, C1R, and $\mathrm{C} 7$ (Fig. 2D).

All the COVID-19 patients were distinguished from influenza patients using hierarchical cluster analysis of the differentiallyexpressed proteins (Fig. 3A). These data suggest that these proteins could be potential biomarkers for early COVID-19 di- agnosis. A large independent cohort should be used to validate these findings.

Prevalent Inflammation and Immune Signaling in Early COVID19 Infection-Twenty-six biological processes were identified from GO analysis of the differentially-expressed proteins in early-stage COVID-19 (Fig. 3B, supplemental Table S4). The biological processes are divided into four classes: (1) immune cell activation and migration, (2) cellular activities, (3) protein signaling that regulate viral infection, and (4) blood functional systems. More specifically, the first class of biological processes includes $\mathrm{T}$ cells, B cells, monocytes, myeloid leukocytes, etc. The second class of biological processes mainly reflects cellular activities, such as endocytosis, membrane protein proteolysis, cell-cell adhesion. The third class of biological processes include signaling pathways that regulate the viral infection, including the MAPK, ERK1/ERK2, JAKSTAT, and PI3K pathways. The fourth class of biological processes is blood functional systems, including inflammation response, complement, coagulation and chemotaxis.

Next, the up- and downregulated signaling pathways in early SARS-CoV-2 infection were further selected using STRING by filtering for differentially-expressed proteins ( $n \geq 10$ ) and a $p$-value less than 0.01 (Fig. 4A, supplemental Table S5). Signaling pathways that were up-regulated the most were cytokine-cytokine receptor interaction, cytokine signaling in immune system, IL-4 and IL-13 signaling and IL17 signaling. Signaling pathways representing the second most up-regulated group were associated with viral infection, including the JAK-STAT, MAPK, and PI3K-Akt signaling pathways. In contrast, neutrophil degranulation, complement cascade, and coagulation cascades were down-regulated in early COVID-19 infection.

The most conserved protein domains within the differentially-expressed proteins were also from the cytokine and chemokine protein family, including the cytokine interleukin-8 like superfamily, chemokine interleukin-8-like domain, fourhelical cytokine-like, core, cysteine-knot cytokine, CC chemokine, conservation site, interleukin-10/19/20/22/24/26 family, interleukin-10 conservation site and interkin-17 family (Fig. $4 B$ ). The second most abundant protein domains were from platelet-derived growth factor (PDGF) conservation site, PDGF/VEGF domain, and growth factor receptor domain 4. In addition, the domains of tyrosine protein kinase (EGF/ERB/ XmrK receptor), receptor L-domain superfamily, and receptor L-domain were identified. By contrast, the domains of downregulated proteins were the sushi/SCR/CCP domain, sushi/ SCR/CCP family, and sushi repeat (SCR repeat).

Functional annotation of the cellular components shows that the upregulated proteins were specifically enriched in cell surface, external side of plasma membrane, vesicle lumen, cytoplasmic vesicle lumen, receptor complex, extracellular matrix, endoplasmic reticulum lumen, plasma membrane part, cytoplasmic vesicle membrane, endosome, whole membrane, intrinsic component of plasma membrane, Golgi 
A

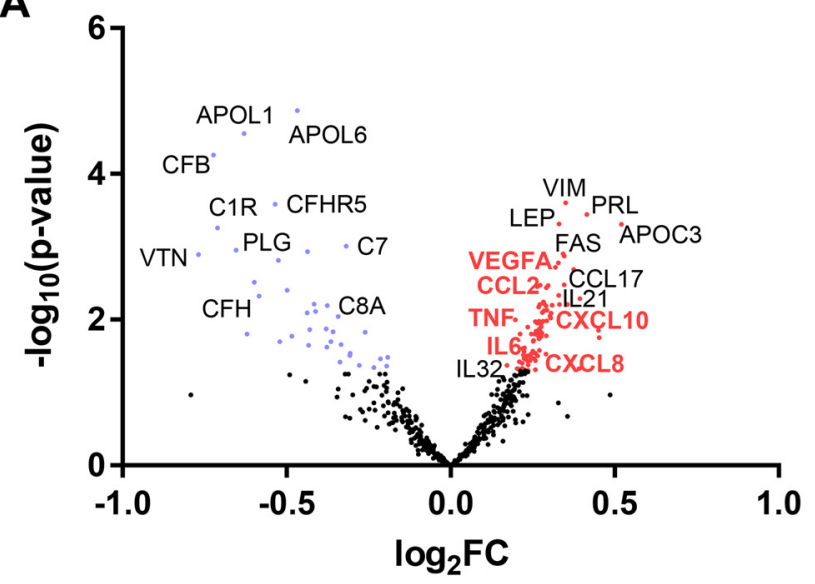

B

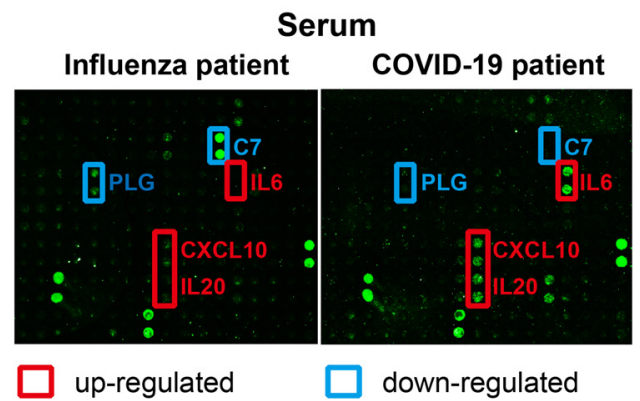

C

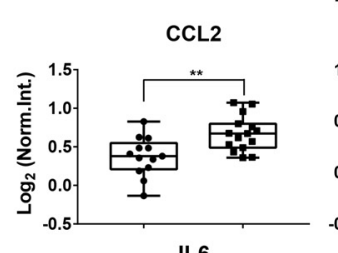

IL6

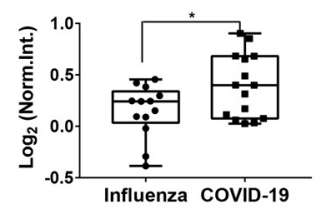

D
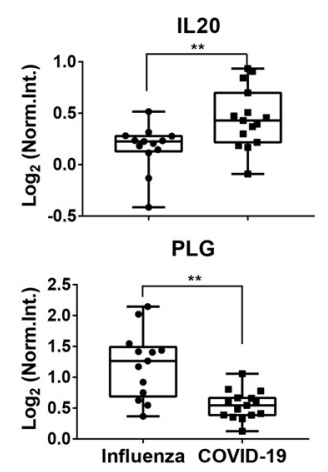

Known biomarker
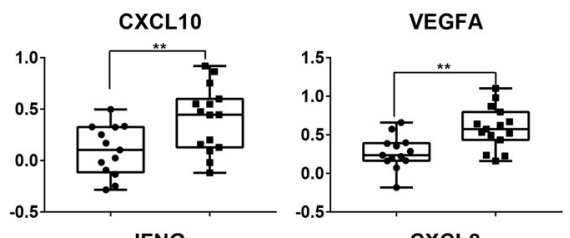

CXCL8
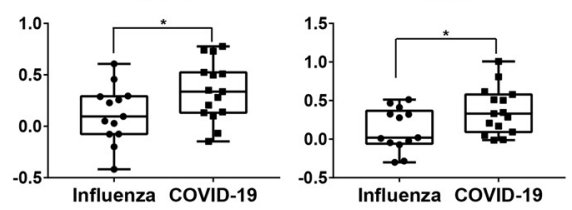

New biomarker
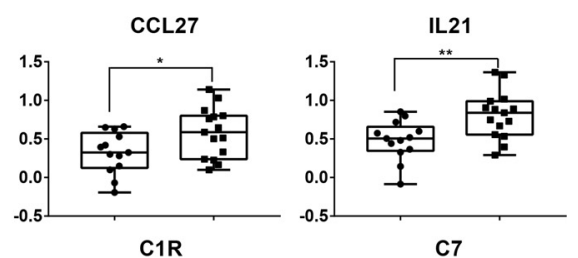

C7
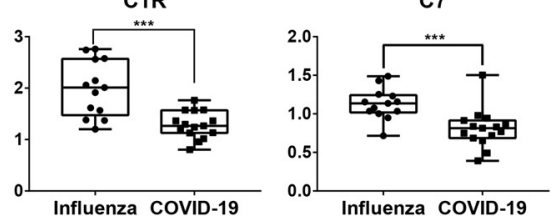

FIG. 2. Detection of proteins associated with early-stage COVID-19. $A$, Volcano plot analysis of COVID-19 associated proteins in serum. Blue and red dots represent down- and up-regulated proteins in early-stage COVID-19, respectively. Protein symbols in red represent the known serum proteins associated with COVID-19; $B$, Representative results of antibody microarray images in the serum of early-stage COVID-19 and influenza patients; $C$, Box plot analysis of known COVID-19 associated serum proteins; $D$, Box plot analysis of newly identified COVID-19 associated serum proteins. ${ }^{*},{ }^{* *}$ and ${ }^{* * *}$ represent the $p$-value less than $0.05,0.01$, and 0.001 , respectively.

apparatus part, integral component of plasma membrane, endoplasmic reticulum part and endoplasmic reticulum. Only one cellular component was enriched in the downregulated protein: the vesicle (Fig. 4C).

To highlight the involvement of cytokines in COVID-19 infection, 29 chemokines, cytokines, or growth factors are involved in the cytokine-cytokine receptor and viral protein interaction with cytokine and cytokine receptor pathways (Fig. 5). These include fifteen chemokines (BAFF, CX3CL1, CCL2, CCL4, CCL4L1, CCL4L2, CCL5, CCL8, CCL10, CCL12, CCL16, CCL17, CCL27, CCL28, CCL32), twelve cytokines (IFNG, IL3, IL6, IL12, IL13, IL17A, IL17B, IL17E, IL19, IL20, IL21, IL32), and two growth factors (TGFB1, NGF).

CCL2 and CXCL10 Medicated Cytokine Signaling Pathways Significantly Correlate with Neutrophil and Lymphocyte Respectively-A comprehensive correlation analysis of the differentially-expressed proteins and clinical indices in early-stage COVID-19 patients was performed (Fig. 6, supplemental Table S6). Protein expression was positively correlated with clinical indices reflecting the liver function (Albumin, Alb; Alanine aminotransferase, ALT; Total bilirubin, TBil), renal function (Creatinine, $\operatorname{Cr}(\mathrm{E})$; Urea), acute myocardial injury (Crea- tine Kinase MB mass, CKMB-mass; Cardiac Troponin I, cTnl; $\mathrm{N}$-terminal pro-Brain Natriuretic Peptide, NT-proBNP; Creatine Kinase, CK), and inflammation and infection (C-reactive protein, CRP; White Blood Cell, WBC; Neutrophil, NEUT) (Fig. 6A). By contrast, the expression of some proteins had a negative correction with the lymphocyte (LY) count, eosinophil percentage (EOS\%) and Direct Bilirubin (DBil) level (Fig. 6B).

Among these clinical indices, NEUT and LY have the largest correlations with 21 and 12 proteins in COVID-19 patients, respectively (Fig. $6 C$ and $6 D$ ). The functional annotation of these proteins using theSTRING database show that the proteins are enriched in the CCL2- and CXCL10-mediated cytokine signaling pathways, respectively (Fig. $6 E$ and 6F, supplemental Table S7).

\section{DISCUSSION}

Understanding the host's response to SARS-CoV-2 infection is crucial to designing a therapeutic regime to efficiently clear the SARS-CoV-2 virus and minimize tissue damage (19). An abundance of evidence has revealed that cytokines play an important role in the severity of COVID-19 symptoms 
A

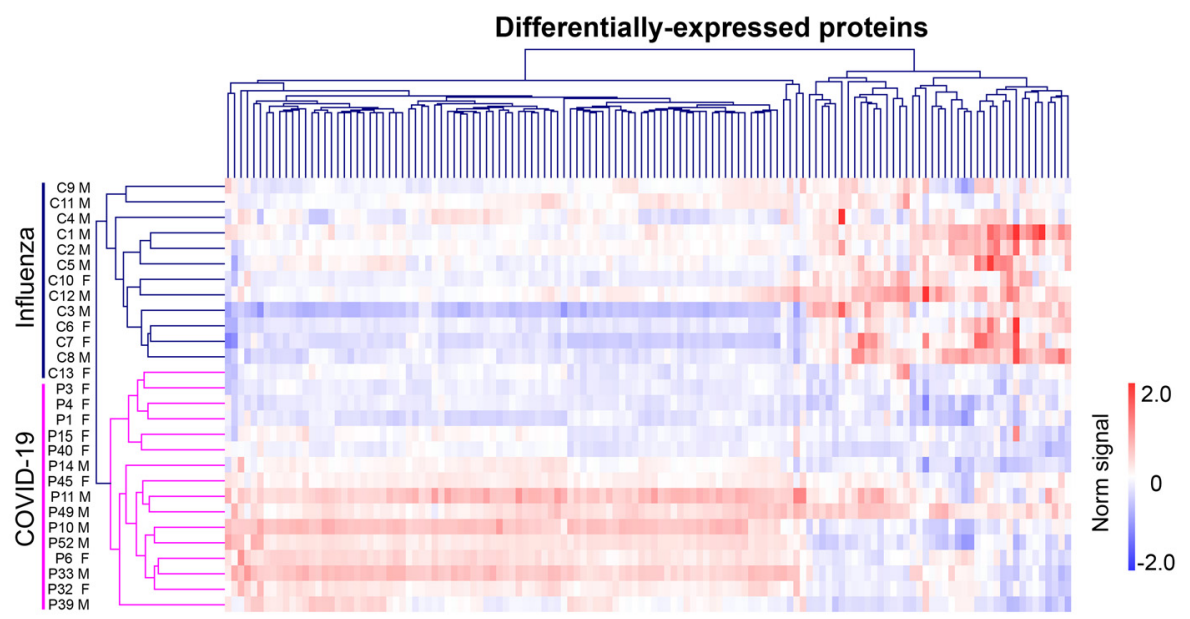

B

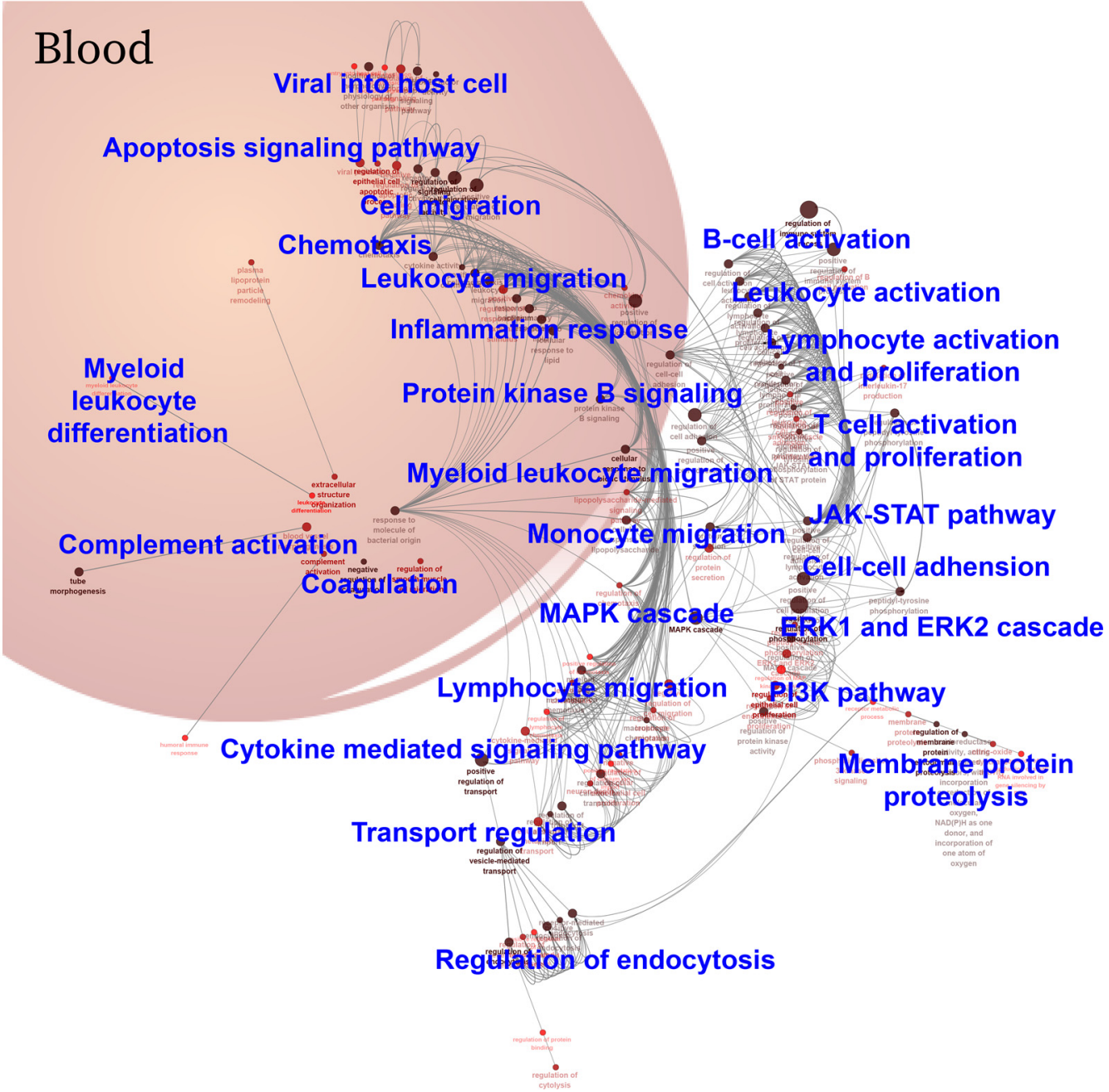

FIG. 3. A landscape of immune signaling in early SARS-CoV-2 infection. A, Hierarchical clustering analysis of differentially-expressed proteins between the COVID-19 and influenza patient groups with a $p$-value $<0.05$ (t-distributed $t$ test). Intensities of proteins were log2-transformed. $B$, GO biological process analysis visualized in Cytoscape. Significantly enriched biological processes were selected using a two-sided hypergeometric test with a p-value $<0.01$. M: male; F: female. 
A

Signaling pathway

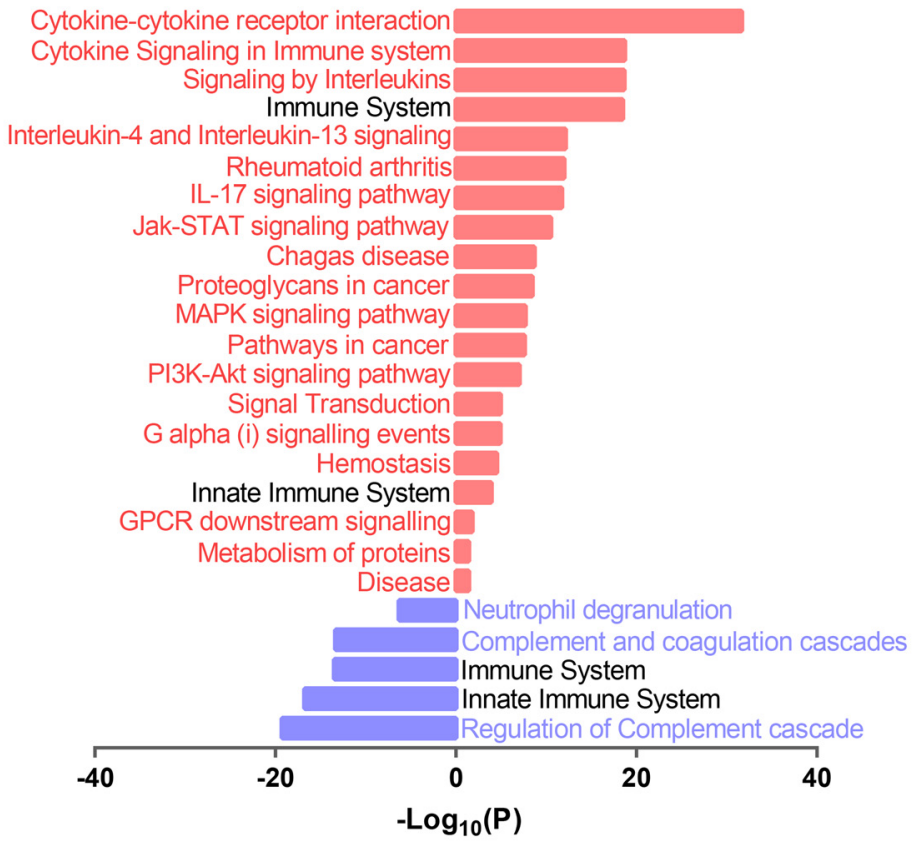

B

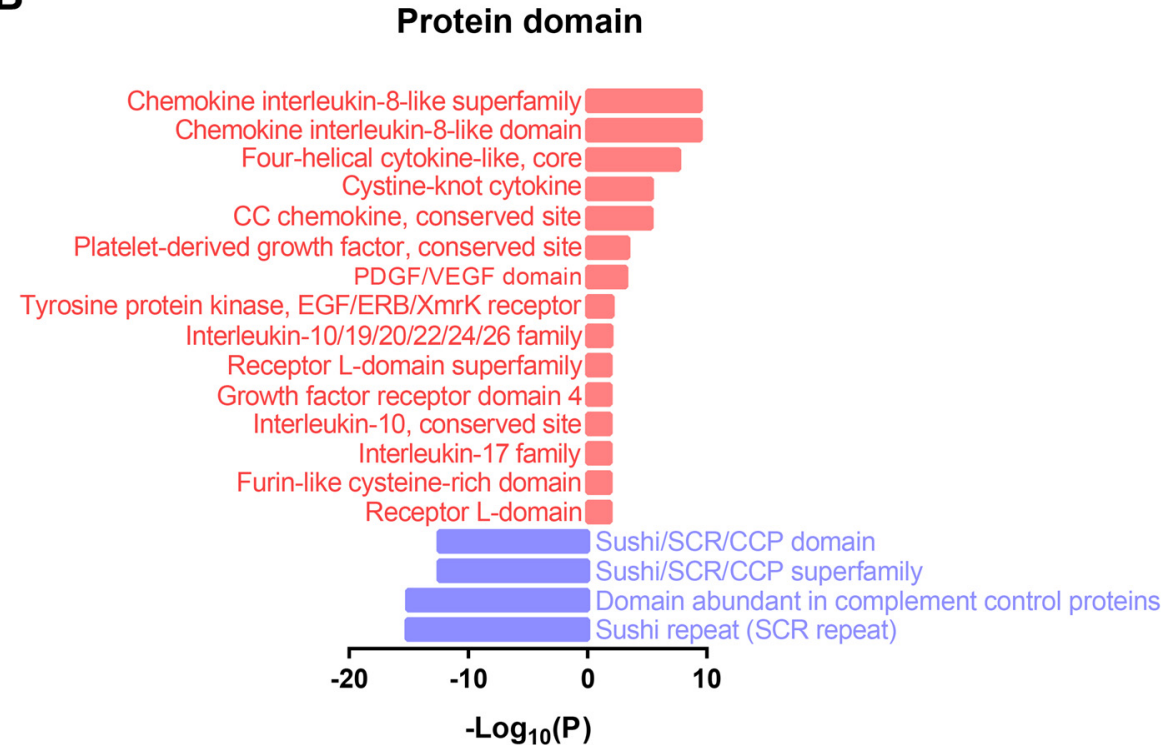

\section{Cellular component}

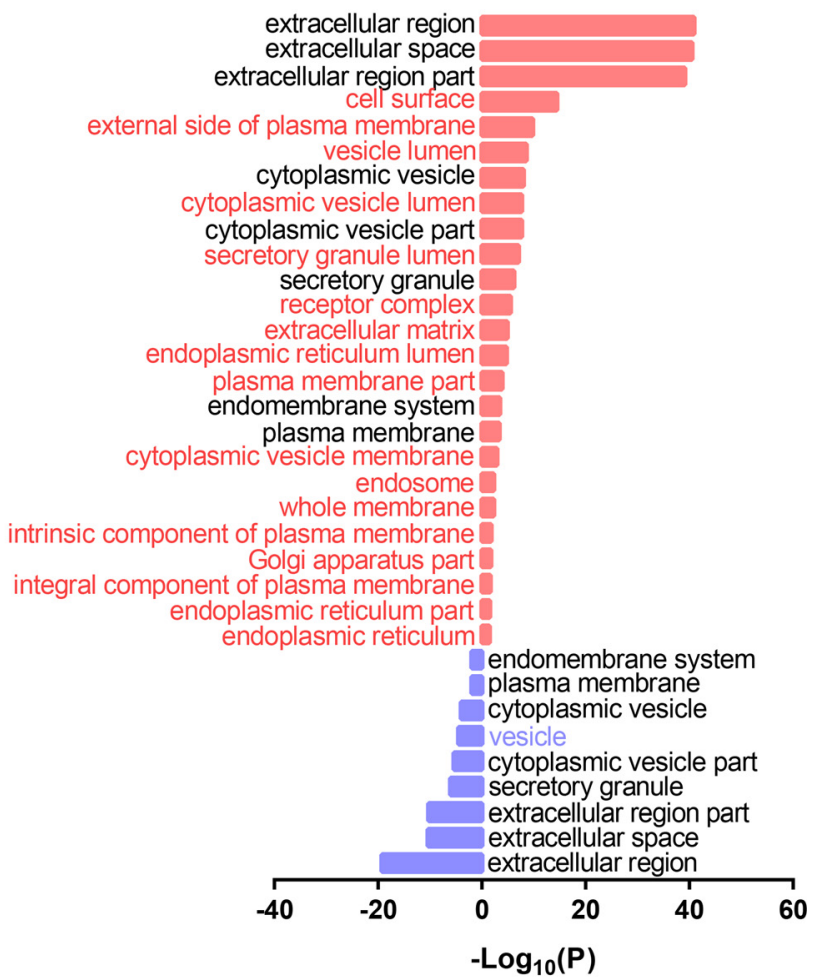

FIG. 4. Functional annotation of the differentially-expressed proteins in early SARS-CoV-2 infection. $A, B$, and $C$, are the significantly altered signaling pathway, protein domain, and cellular component identified by antibody microarrays in early-stage COVID-19, respectively. Pvalues were calculated by two-sided hypergeometric test based on the KEGG/Reactome/InterPro database and GO terms. Up-regulated and down-regulated pathways are indicated in red (right) and blue (left) bars.

$(8,19,20)$. However, the overall protein expression changes in serum during early SARS-CoV-2 infection is unknown.

To address this concern, we fabricated a high-density antibody microarray to profile the expression of 532 serological proteins of early-stage COVID-19 and influenza patients (Fig. 1). One primary advantage of antibody arrays compared with another popular protein detection tool, MS, is that depletion of high abundance proteins is unnecessary and ion suppression is not a concern. Thus, low abundance proteins in serum can be identified with antibody arrays with minimal sample processing (10). All antibodies used for fabricating microarray had been characterized by the vendors using ELISA, immunoprecipitation (IP), immunofluorescence (IF), immunohistochemistry $(\mathrm{IHC})$ or flow cytometry. Furthermore, two antibodies (IL- 
A
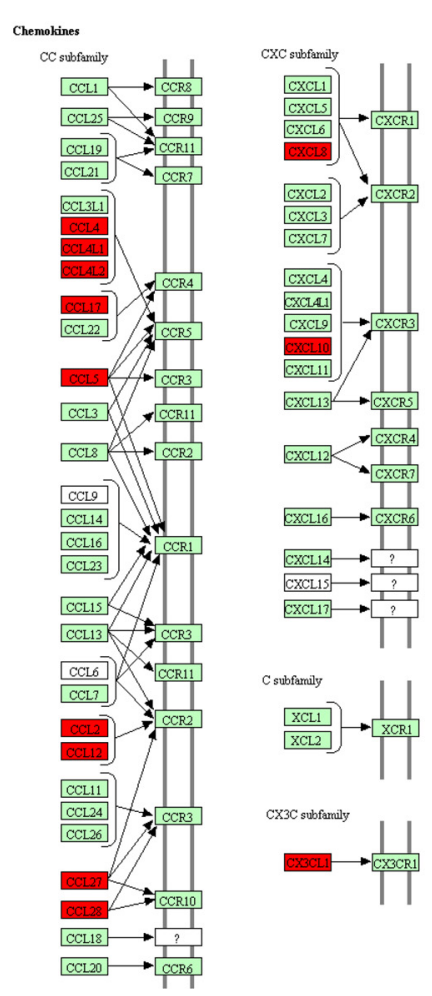

\section{Cytokine-cytokine receptor interaction}

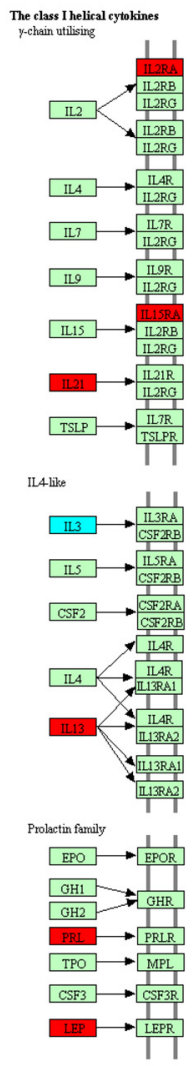

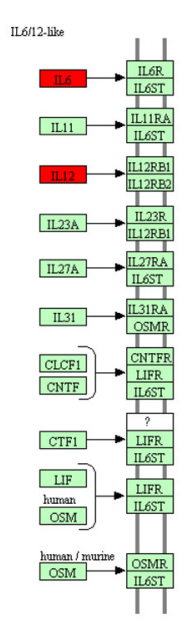
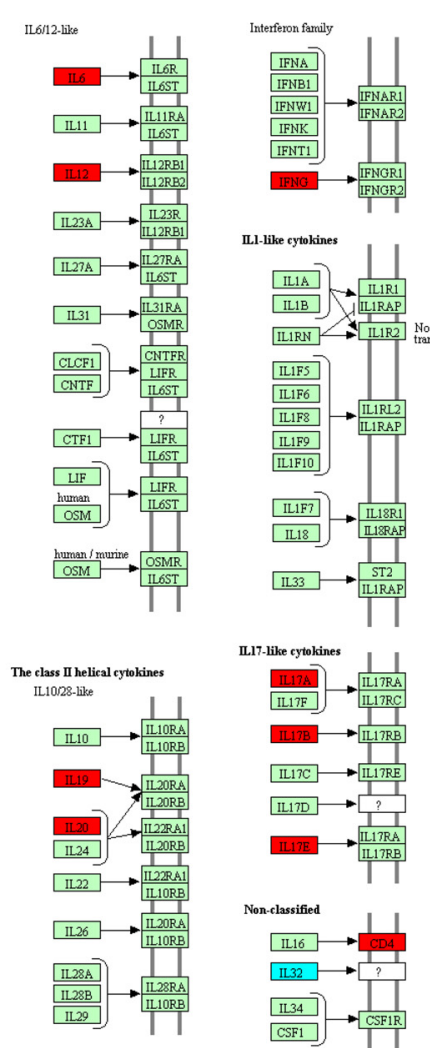

TNF Fanily

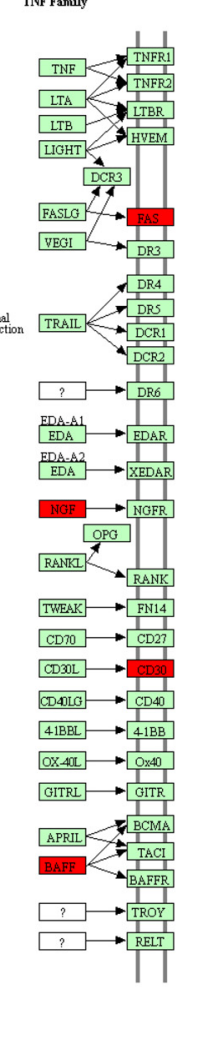

TGF- $\beta$ fanily

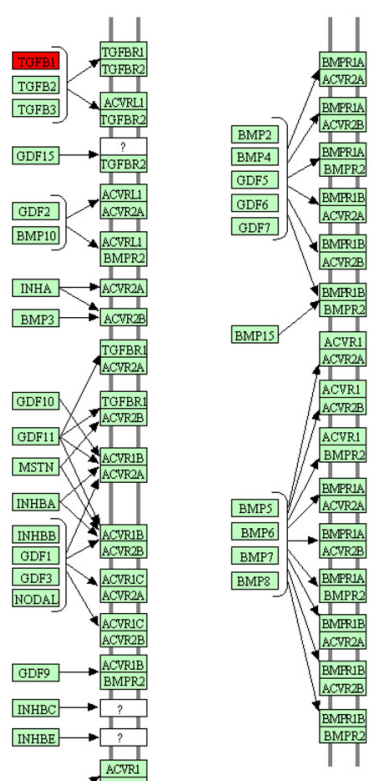

B

\section{Viral protein interaction with cytokine and cytokine receptor}
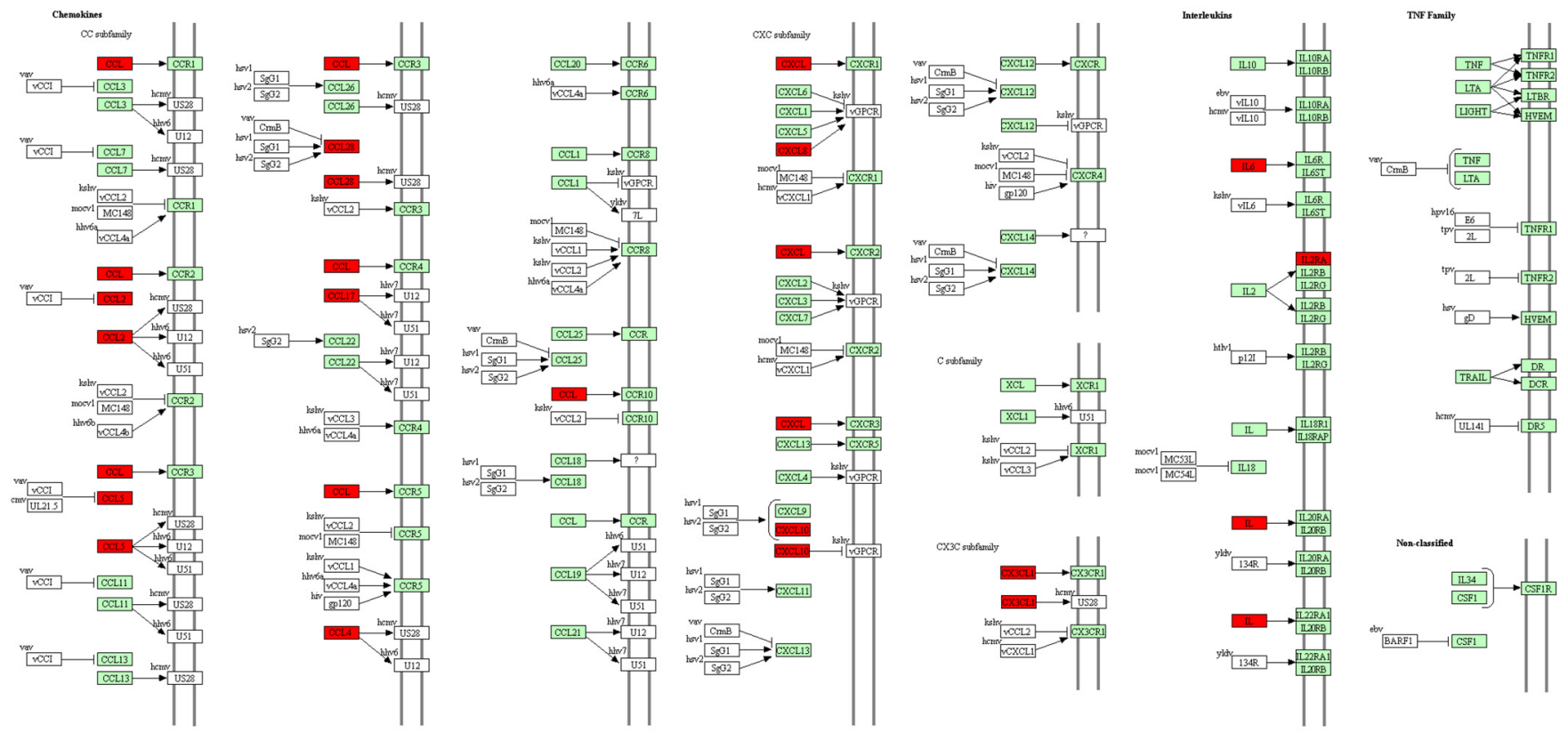

up-regulated

down-regulated

FIG. 5. The cytokine mediated signaling pathways associated with early SARS-CoV-2 infection. $A$, Cytokine-cytokine receptor interaction; $B$, Viral protein interaction with cytokines and cytokine receptors. Red and blue boxes represent up- and down-regulated genes, respectively. 
A

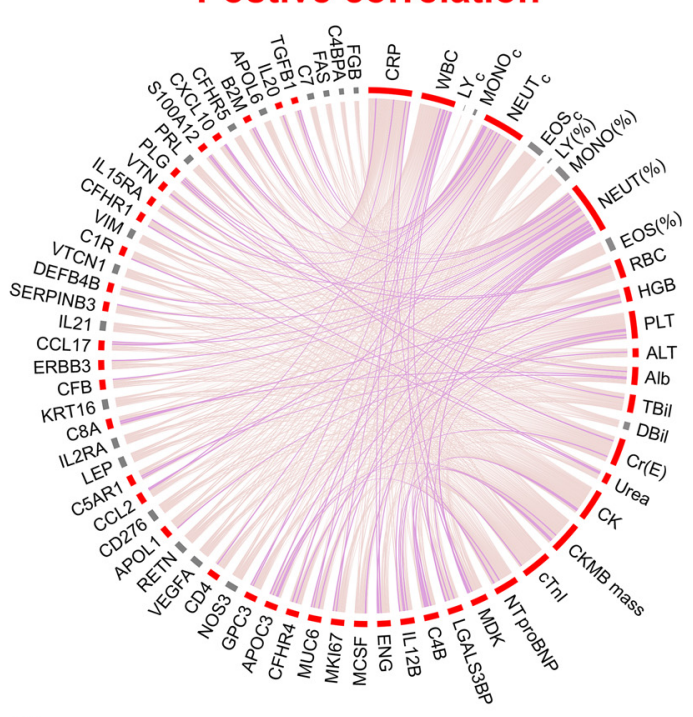

C

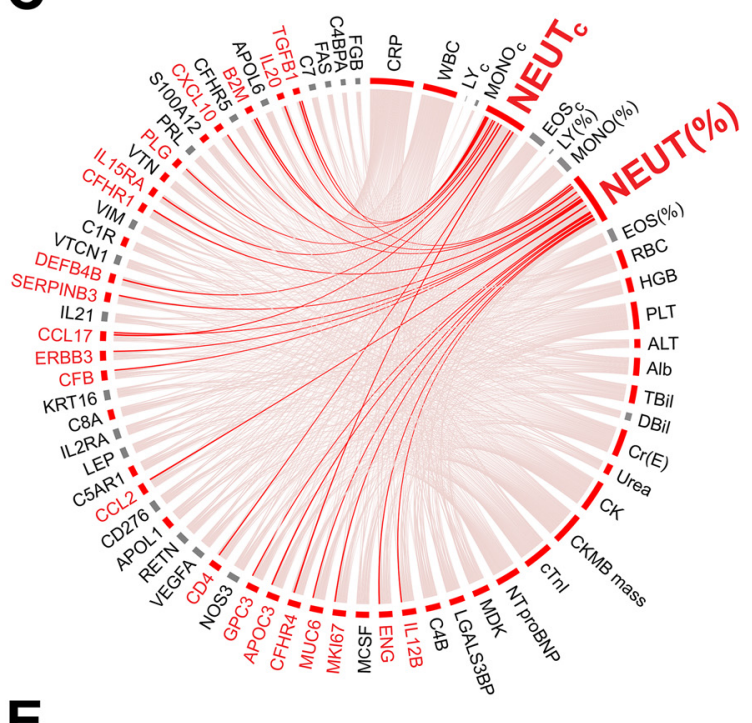

$\mathbf{E}$

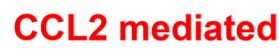

cytokine signaling pathway

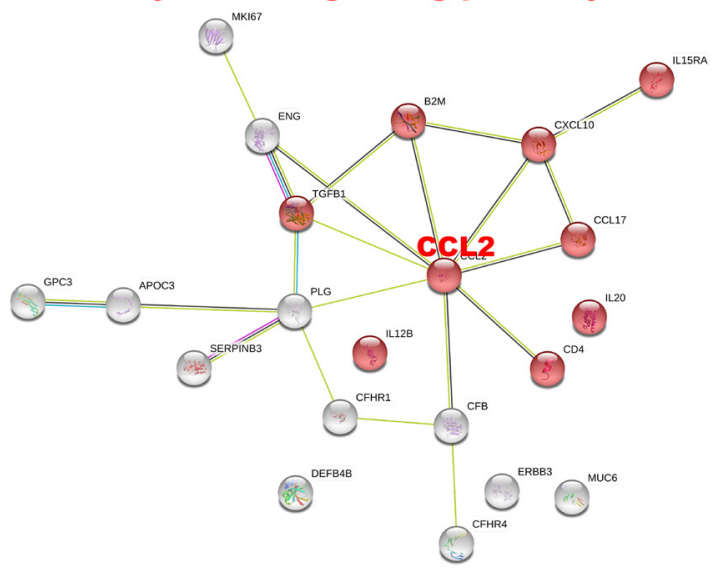

B Negative correlation

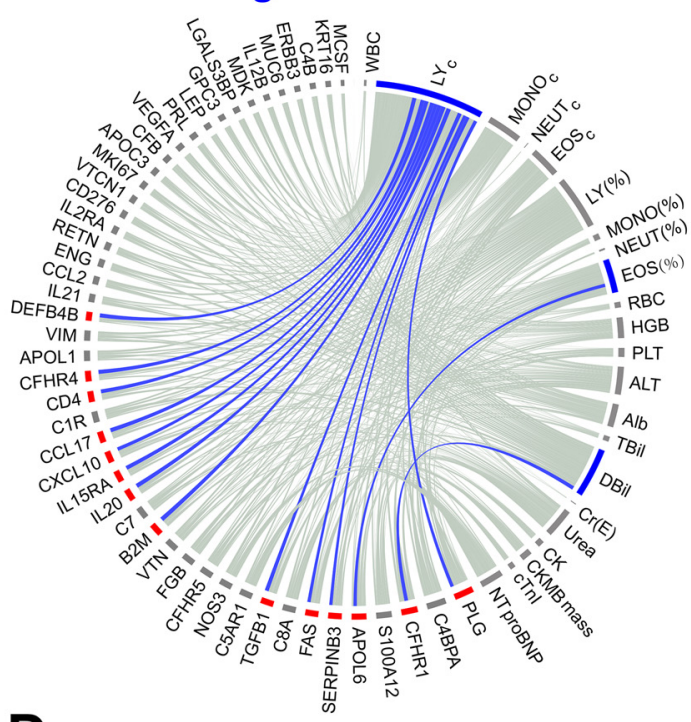

D

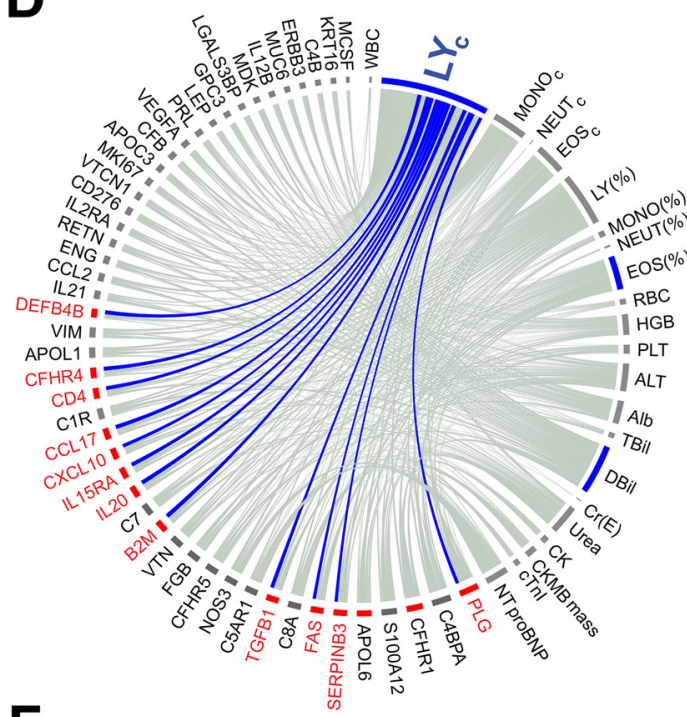

CXCL10 mediated cytokine signaling pathway

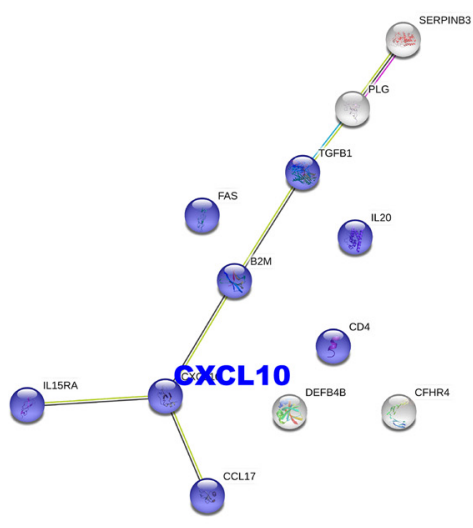


17A and TNF) were randomly selected and confirmed their specificity to the appropriate target using a protein array in our previous study of psoriasis disease (10).

We found that differentially-expressed proteins $(n=125$ $p$-value $<0.05$ ) (Fig. 2) participate in a broad range of biological processes associated with viral infection, inflammation, immune cell activation and migration, and the complement and coagulation processes (Fig. 3B). Changes in the complement and coagulation cascades have also been identified in early SARS-CoV-2 infection and severe COVID-19 patients (21-24). Our data reveal that activation of viral infection pathways (MAPK, ERK1/ERK2, JAK-STAT, PI3K) occurs in acute COVID-19 infection. Previous studies have shown that the MAPK signaling pathway is a major immune response to SARS-CoV-2 infection, and that the ERK and PI3K signaling pathways play a critical role in MERS-CoV and SARS-CoV pathogenesis (25-27).

We show that cytokine-mediated signaling pathways are the major class of dysregulated pathways in early SARSCoV-2 infection (Fig. $4 A$ and $4 B$, Fig. 5). These pathways also play integral roles in SARS-CoV-1 infection (28). The expression changes of these cytokines (i.e. IL6, IL17, CCL2) indicate that pro-inflammation may occur in early stages of SARSCoV-2 infection (Fig. 1A, Table I). In addition, our study identified extensive up-regulation of chemokines, which are often stimulated by pro-inflammatory cytokines and mainly function as chemoattractants for effector cells (e.g. leukocytes, recruiting monocytes, neutrophils) from the blood to sites of infection or tissue damage.

The CCL2- and CXCL10-mediated cytokine signaling pathways, which are known to be involved in viral infections, were enriched in a subset of differentially-expressed proteins in early SARS-CoV-2 infection (Fig. 6C-6F). CCL2 is a CC chemokine that attracts monocytes, memory $T$ lymphocytes, and basophils, and is associated with lung inflammatory disorders, including acute respiratory distress syndrome, asthma, and pulmonary fibrosis. Notably, these inflammatory disorders and pulmonary infiltration are associated with the progressive respiratory failure and death of SARS patients (29). Furthermore, CCL2 can act as an autocrine factor that promotes viral replication in infected macrophages, and CCL2 neutralization inhibits HIV-1 replication in monocyte-derived macrophages (30). Interestingly, a novel class of small molecule inhibitor, bindarit, alleviates inflammation caused by Chikungunya and Ross River viruses by reducing CCL2 synthesis in animal models $(31,32)$. CXCL10 is a ligand for the CXCR3 receptor, the activation of which results in the recruitment of $\mathrm{T}$ cells and the perpetuation of mucosal inflammation. Tacrolimus (FK506), a macrolide immunosuppressive agent isolated from Streptomyces tsukubaensis, has been found to suppress CCL2 and CXCL10 expression in human colonic myofibroblasts (33). All the results combined suggest that CCL2 and CXCL10 may have the potential to be used as anti-inflammation targets for COVID-19 therapy (9, 34).

Interestingly, in Fig. $3 A$, there are two distinct branches of COVID-19 patients in the clustering analysis. The first group of five patients were all female, whereas the all male patients were clustered in the second group. This may indicate sex differences in the immune responses against SARS-CoV-2 infection. The results are accord to the reports in which male patients displayed higher plasma levels of innate immune cytokines and the male sex is a risk factor for the severity of COVID-19 patient $(35,36)$.

There are three limitations in this study. First, the number of serum samples was limited; thus, the biomarkers identified in our study should be validated in a large independent clinical cohort. Second, protein detection depends on the sensitivity and specificity of the capture antibodies immobilized on the microarray. Third, serological proteins of earlystage COVID-19 patients were only compared with earlystage influenza patients. In the future, protein profiling of COVID-19 patients should be examined over the entire course of infection. In addition, the profiles should be compared with healthy patients and patients infected with different viruses.

Our study comprehensively profiled the serological proteins of early SARS-CoV-2, revealing a new understanding of the inflammation and immune signaling that occurs. Our data also identified potential biomarkers that could be used to diagnose COVID-19 patients and design effective treatment.

Acknowledgments-We thank Dr. Brianne Petritis for her critical review and editing of this manuscript.

Funding and additional information-This research was supported by grants from the National Key R\&D Program of China (2020YFE0202200), National Natural Science Foundation of China Grants (81671618, 81871302, 81673040, 31870823), CAMS Innovation Fund for Medical Sciences (CIFMS) (2017I2M-3-001, 2017-I2M-B\&R-01), the State Key Laboratory of Proteomics (SKLP-C202001, SKLP-O201703, SKLP-K201505), the Beijing Municipal Education Commission and the National

FIG. 6. Correlation network of early COVID-19 specific proteins and clinical indices. $A$, and $B$, are the positive and negative correlations of early SARS-CoV-2 infections and twenty clinical indices using circus, respectively. Correlations with statistical significance $(p$-value $<0.05)$ are indicated in pink. Nonsignificant $(p$-value $\geq 0.05)$ positive and negative correlations are indicated in red and blue, respectively. $C$, and $D$, are proteins correlated with neutrophils and lymphocytes, respectively. $E$, and $F$, are the protein-protein interaction networks of COVID-19 proteins that are positively and negatively associated, respectively, with neutrophils and lymphocytes. The protein-protein interactions and KEGG pathway analysis were performed in the STRING database (https://string-db.org/). 
Program on Key Basic Research Project (2018YFA0507503, 2017YFC0906703, 2018ZX09733003).

Author contributions-X.H., Y.L., and X.W. provided the clinical samples. X.Z., H.W., D.W., J.D., T.L., and M.X. prepared the microarrays. X.H., X.Z., and M.L. executed microarray experiments. X.Z., D.W., T.L., H.D., and X.Y. executed the statistical and structural analysis. X.Y., Y.X., and Y.L. conceived the idea, designed experiments, analyzed the data and wrote the manuscript.

Conflict of interest- The authors declare that they have no conflicts of interest with the contents of this article.

Abbreviations - The abbreviations used are: COVID-19, Coronavirus disease 2019; SARS-CoV-2, severe acute respiratory syndrome coronavirus 2 .

Received May 13, 2020, and in revised form, July 22, 2020 Published, MCP Papers in Press, August 10, 2020, DOI 10.1074/mcp. RP120.002128

\section{REFERENCES}

1. Zhu, N., Zhang, D., Wang, W., Li, X., Yang, B., Song, J., Zhao, X., Huang, B., Shi, W., Lu, R., Niu, P., Zhan, F., Ma, X., Wang, D., Xu, W., Wu, G., Gao, G. F., and Tan, W, China Novel Coronavirus Investigating and Research Team. (2020) China Novel Coronavirus, I., and Research, T. (2020) A Novel Coronavirus from Patients with Pneumonia in China. N Engl. J. Med. 382, 727-733

2. Wang, C., Horby, P. W., Hayden, F. G., and Gao, G. F. (2020) A novel coronavirus outbreak of global health concern. The Lancet 395, 470-473

3. Huang, C., Wang, Y., Li, X., Ren, L., Zhao, J., Hu, Y., Zhang, L., Fan, G., Xu, J., Gu, X., Cheng, Z., Yu, T., Xia, J., Wei, Y., Wu, W., Xie, X., Yin, W., Li, H., Liu, M., Xiao, Y., Gao, H., Guo, L., Xie, J., Wang, G., Jiang, R., Gao, Z., Jin, Q., Wang, J., and Cao, B. (2020) Clinical features of patients infected with 2019 novel coronavirus in Wuhan. China. The Lancet 395, 497-506

4. Wu, Z., and McGoogan, J. M. (2020) Characteristics of and important lessons from the coronavirus disease 2019 (COVID-19) outbreak in China Summary of a Report of 72314 cases from the Chinese Center for Disease Control and Prevention. JAMA 323, 1239-1242

5. Chen, N., Zhou, M., Dong, X., Qu, J., Gong, F., Han, Y., Quu, Y., Wang, J., Liu, Y., Wei, Y., Xia, J., Yu, T., Zhang, X., and Zhang, L. (2020) Characteristics of and important lessons from the coronavirus disease 2019 (COVID-19) outbreak in china summary of a report of 72314 cases from the Chinese Center for Disease Control and Prevention. Lancet 395, 507-513

6. Ruan, Q., Yang, K., Wang, W., Jiang, L., and Song, J. (2020) Clinical predictors of mortality due to COVID-19 based on an analysis of data of 150 patients from Wuhan. Intensive Care Med. 46, 1294-1293

7. Mehta, P., McAuley, D. F., Brown, M., Sanchez, E., Tattersall, R. S., and Manson, J. J. (2020) COVID-19: consider cytokine storm syndromes and immunosuppression. Lancet 395, 1033-1034

8. Huang, C., Wang, Y., Li, X., Ren, L., Zhao, J., Hu, Y., Zhang, L., Fan, G., Xu, J., Gu, X., Cheng, Z., Yu, T., Xia, J., Wei, Y., Wu, W., Xie, X., Yin, W., Li, H., Liu, M., Xiao, Y., Gao, H., Guo, L., Xie, J., Wang, G., Jiang, R., Gao, Z., Jin, Q., Wang, J., and Cao, B. (2020) Clinical features of patients infected with 2019 novel coronavirus in Wuhan, China. Lancet. 395, 497-506

9. Zhang, W., Zhao, Y., Zhang, F., Wang, Q., Li, T., Liu, Z., Wang, J., Qin, Y., Zhang, X., Yan, X., Zeng, X., and Zhang, S. (2020) The use of anti-inflammatory drugs in the treatment of people with severe coronavirus disease 2019 (COVID-19): The Perspectives of clinical immunologists from China. Clin. Immunol. 214, 108393

10. Xu, M., Deng, J., Xu, K., Zhu, T., Han, L., Yan, Y., Yao, D., Deng, H., Wang, D., Sun, Y., Chang, C., Zhang, X., Dai, J., Yue, L., Zhang, Q., Cai, X., Zhu, Y., Duan, H., Liu, Y., Li, D., Zhu, Y., Radstake, T., Balak, D. M. W., Xu, D., Guo, T., Lu, C., and Yu, X. (2019) In-depth serum proteomics reveals bio- markers of psoriasis severity and response to traditional Chinese medicine. Theranostics 9, 2475-2488

11. Mi, H., Poudel, S., Muruganujan, A., Casagrande, J. T., and Thomas, P. D. (2016) PANTHER version 10: expanded protein families and functions, and analysis tools. Nucleic Acids Res. 44, D336-D342

12. Bindea, G., Mlecnik, B., Hackl, H., Charoentong, P., Tosolini, M., Kirilovsky, A., Fridman, W. H., Pages, F., Trajanoski, Z., and Galon, J. (2009) ClueGO: a Cytoscape plug-in to decipher functionally grouped gene ontology and pathway annotation networks. Bioinformatics 25, 1091-1093

13. Franz, M., Lopes, C. T., Huck, G., Dong, Y., Sumer, O., and Bader, G. D. (2016) Cytoscape.js: a graph theory library for visualisation and analysis. Bioinformatics 32, 309-311

14. Szklarczyk, D., Franceschini, A., Wyder, S., Forslund, K., Heller, D., HuertaCepas, J., Simonovic, M., Roth, A., Santos, A., Tsafou, K. P., Kuhn, M., Bork, P., Jensen, L. J., and von Mering, C. (2015) STRING v10: proteinprotein interaction networks, integrated over the tree of life. Nucleic Acids Res. 43, D447-D452

15. Chu, V. T., Gottardo, R., Raftery, A. E., Bumgarner, R. E., and Yeung, K. Y. (2008) $\mathrm{MeV}+\mathrm{R}$ : using MeV as a graphical user interface for Bioconductor applications in microarray analysis. Genome Biol. 9, R118

16. Yu, X., Wallstrom, G., Magee, D. M., Qiu, J., Mendoza, D. E., Wang, J., Bian, X., Graves, M., and LaBaer, J. (2013) Quantifying antibody binding on protein microarrays using microarray nonlinear calibration. BioTechniques $\mathbf{5 4}$, 257-264

17. Schett, G., Sticherling, M., and Neurath, M. F. (2020) COVID-19: risk for cytokine targeting in chronic inflammatory diseases? Nat. Rev. Immunol. 20, 271-272

18. Wu, D., and Yang, X. O. (2020) TH17 responses in cytokine storm of COVID19: An emerging target of JAK2 inhibitor Fedratinib. J. Microbiol. Immunol. Infect. 53, 368-370

19. Shi, Y., Wang, Y., Shao, C., Huang, J., Gan, J., Huang, X., Bucci, E., Piacentini, M., Ippolito, G., and Melino, G. (2020) COVID-19 infection: the perspectives on immune responses. Cell Death Differ. 27, 1451-1454

20. Chen, G., Wu, D., Guo, W., Cao, Y., Huang, D., Wang, H., Wang, T., Zhang, X., Chen, H., Yu, H., Zhang, X., Zhang, M., Wu, S., Song, J., Chen, T., Han, M., Li, S., Luo, X., Zhao, J., and Ning, Q. (2020) Clinical and immunological features of severe and moderate coronavirus disease. J. Clin. Invest. 2019

21. Tanaka, T., Narazaki, M., and Kishimoto, T. (2016) Immunotherapeutic implications of IL-6 blockade for cytokine storm. Immunotherapy 8, 959-970

22. Tang, N., Li, D., Wang, X., and Sun, Z. (2020) Abnormal coagulation parameters are associated with poor prognosis in patients with novel coronavirus pneumonia. J. Thromb. Haemost. 18, 844-847

23. Campbell, C. M., and Kahwash, R. (2020) Will complement inhibition be the new target in treating COVID-19. Related systemic thrombosis? Circulation 141, 1739-1741

24. Risitano, A. M., Mastellos, D. C., Huber-Lang, M., Yancopoulou, D., Garlanda, C., Ciceri, F., and Lambris, J. D. (2020) Complement as a target in COVID-19?. Nat. Rev. Immunol. 20, 448-448

25. Huang, L., Shi, Y., Gong, B., Jiang, L., Liu, X., Yang, J., Tang, J., You, C., Jiang, Q., Long, B., Zeng, T., Luo, M., Zeng, F., Zeng, F., Wang, S., Yang, $X$. , and Yang, Z. (2020) Blood single cell immune profiling reveals the interferon-MAPK pathway mediated adaptive immune response for COVID-19. medRxiv doi: https://doi.org/

26. Kindrachuk, J., Ork, B., Hart, B. J., Mazur, S., Holbrook, M. R., Frieman, M. B., Traynor, D., Johnson, R. F., Dyall, J., Kuhn, J. H., Olinger, G. G., Hensley, L. E., and Jahrling, P. B. (2015) Antiviral potential of ERK/MAPK and PI3K/AKT/mTOR signaling modulation for Middle East respiratory syndrome coronavirus infection as identified by temporal kinome analysis. Antimicrob. Agents Chemother. 59, 1088-1099

27. Mizutani, T., Fukushi, S., Saijo, M., Kurane, I., and Morikawa, S. (2005) JNK and $\mathrm{Pl} 3 \mathrm{~K} / \mathrm{Akt}$ signaling pathways are required for establishing persistent SARS-CoV infection in Vero E6 cells. Biochim. Biophys. Acta 1741, 4-10

28. Channappanavar, R., Fehr, A. R., Vijay, R., Mack, M., Zhao, J., Meyerholz, D. K., and Perlman, S. (2016) Dysregulated type I interferon and inflammatory monocyte-macrophage responses cause lethal pneumonia in SARSCoV-infected mice. Cell Host Microbe. 19, 181-193

29. Chen, I. Y., Chang, S. C., Wu, H. Y., Yu, T. C., Wei, W. C., Lin, S., Chien, C. L., and Chang, M. F. (2010) Upregulation of the chemokine (C-C motif) ligand 2 via a severe acute respiratory syndrome coronavirus spike-ACE2 signaling pathway. J. Virol. 84, 7703-7712 
30. Sabbatucci, M., Covino, D. A., Purificato, C., Mallano, A., Federico, M., Lu, J., Rinaldi, A. O., Pellegrini, M., Bona, R., Michelini, Z., Cara, A., Vella, S., Gessani, S., Andreotti, M., and Fantuzzi, L. (2015) Endogenous CCL2 neutralization restricts HIV-1 replication in primary human macrophages by inhibiting viral DNA accumulation. Retrovirology 12, 4

31. Rulli, N. E., Guglielmotti, A., Mangano, G., Rolph, M. S., Apicella, C., Zaid, A., Suhrbier, A., and Mahalingam, S. (2009) Amelioration of alphavirusinduced arthritis and myositis in a mouse model by treatment with bindarit, an inhibitor of monocyte chemotactic proteins. Arthritis Rheum. 60, 25132523

32. Rulli, N. E., Rolph, M. S., Srikiatkhachorn, A., Anantapreecha, S., Guglielmotti, A., and Mahalingam, S. (2011) Protection from arthritis and myositis in a mouse model of acute chikungunya virus disease by bindarit, an inhibitor of monocyte chemotactic protein-1 synthesis. J. Infect. Dis. 204, 1026-1030

33. Aomatsu, T., Imaeda, H., Takahashi, K., Fujimoto, T., Kasumi, E., Yoden, A., Tamai, H., Fujiyama, Y., and Andoh, A. (2012) Tacrolimus (FK506) sup- presses TNF-alpha-induced CCL2 (MCP-1) and CXCL10 (IP-10) expression via the inhibition of p38 MAP kinase activation in human colonic myofibroblasts. Int. J. Mol. Med. 30, 1152-1158

34. Liu, M., Guo, S., Hibbert, J. M., Jain, V., Singh, N., Wilson, N. O., and Stiles, J. K. (2011) CXCL10/IP-10 in infectious diseases pathogenesis and potential therapeutic implications. Cytokine Growth Factor Rev. 22, 121-130

35. Takahashi, T., Wong, P., Ellingson, M., Lucas, C., Klein, J., Israelow, B., Silva, J., Oh, J., Mao, T., Tokuyama, M., Lu, P., Venkataraman, A., Park, A., Liu, F., Meir, A., Sun, J., Wang, E., Wyllie, A. L., Vogels, C. B. F., Earnest, R., Lapidus, S., Ott, I., Moore, A., Casanovas, A., Dela Cruz, C., Fournier, J., Odio, C., Farhadian, S., Grubaugh, N., Schultz, W., Ko, A., Ring, A., Omer, S., and Iwasaki, A. (2020) Sex differences in immune responses to SARSCoV-2 that underlie disease outcomes. medRxiv: https://doi.org/10.1101/ 2020.06.06.20123414

36. Scully, E. P., Haverfield, J., Ursin, R. L., Tannenbaum, C., and Klein, S. L. (2020) Considering how biological sex impacts immune responses and COVID-19 outcomes. Nat. Rev. Immunol. 20, 442-447 